\title{
Combined inhibition of sonic Hedgehog signaling and histone deacetylase is an effective treatment for liver cancer
}

\author{
JINGMIN LI ${ }^{1 *}$, HENG CAI $^{*}$, HONGXING LI ${ }^{1}$, YANGUO LIU ${ }^{2}$, YIRONG WANG ${ }^{3}$, \\ YAN SHI $^{1}$, YAN SUN ${ }^{2}$, HAORAN SONG $^{1}$ and DONG WANG ${ }^{1}$ \\ ${ }^{1}$ Department of Histology and Embryology, Binzhou Medical University; \\ Departments of ${ }^{2}$ Surgery and ${ }^{3}$ Radiotherapy, Yantai Shan Hospital, Yantai, \\ Shandong 264003, P.R. China
}

Received July 5, 2018; Accepted December 13, 2018

DOI: $10.3892 /$ or.2019.6982

\begin{abstract}
Clinical trials have revealed that inhibition of sonic Hedgehog (SHH) signaling or histone deacetylase (HDAC) holds promise as a treatment for liver cancer. Based on our previous results, it was hypothesized that dual inhibition of SHH and HDAC may contribute to more efficient targeting of this disease. The effect of SHH inhibitor vismodegib as a single-agent or in combination with HDAC inhibitor entinostat was evaluated by Cell Counting Kit-8 (CCK-8) and flow cytometric assays, as well as immunoblotting. The synergistic effect on cell viability was assessed by combination indexes. Ex vivo cultured liver cancer tissues from a patient were treated with vismodegib as a single-agent or in combination with entinostat, and analyzed by histological and immunohistochemical methods. The results revealed that the dual use of the SHH inhibitor and the HDAC inhibitor effectively synergized to inhibit proliferation, and promote apoptosis in liver cancer cells. Furthermore, the effect of the combination of these drugs was confirmed in an ex vivo culture of human liver cancer tissue. Mechanistically, combined use of SHH and HDAC inhibitors resulted in significantly greater downregulation of $\mathrm{SHH}$ and $\mathrm{PI} 3 \mathrm{~K} / \mathrm{mTOR}$ signaling. In conclusion, the combined use of SHH signaling and HDAC inhibitors may be an effective therapeutic strategy for liver cancer.
\end{abstract}

Correspondence to: Dr Dong Wang, Department of Histology and Embryology, Binzhou Medical University, 346 Guanhai Road, Yantai, Shandong 264003, P.R. China

E-mail: wangdby@163.com

*Joint first authorship

Key words: liver cancer, sonic Hedgehog, histone deacetylases, sonic Hedgehog inhibitor, histone deacetylase inhibitor

\section{Introduction}

Liver cancer is commonly diagnosed, and the 5-year relative survival rate is only $18 \%(1,2)$. Current treatments applicable for liver cancer, include surgery, transcatheter arterial chemoembolization and chemotherapy (3). In recent years, the efficacy of agents that selectively target critical signaling pathways has been assessed in several clinical trials, however, no relevant improvement has been achieved to date $(3,4)$. Therefore, it is urgent to identify therapeutic strategies for more effective therapy of liver cancer.

Recently, the activation of sonic Hedgehog (SHH) signaling has been implicated in liver cancer (5). It was revealed to play a crucial role in the initiation and maintenance of liver cancer and contribute to chemotherapeutic resistance (6). The $\mathrm{SHH}$ signaling pathway is initiated by the binding of the patched (Ptch) receptor, which in turn relieves smoothened (Smo) receptor from inhibition. Smo then triggers a series of intracellular events, resulting in the activation of downstream target genes including the glioma-associated oncogene homolog (Gli), which are the early transcriptional targets of $\mathrm{SHH}$ signaling $(7,8)$. It has been determined that blocking SMO can inhibit the activity of the SHH signaling pathway, and SMO has been used as a target to develop related drugs for cancer treatment (7). It was reported that Smo antagonists including cyclopamine and vismodegib could inhibit the growth of tumors (9). Vismodegib (GDC0449) has been approved by the U.S. Food and Drug Administration (FDA) for the treatment of metastatic or locally advanced unresectable basal cell carcinoma (10).

Several studies have revealed that $\mathrm{SHH}$ regulates sustained activation of histone deacetylases (HDACs) which is required for cell growth $(11,12)$. Liver cancer patients with overexpression of HDAC1 exhibited higher incidence of cancer cell invasion, poorer histological differentiation, and a low survival rate $(13,14)$. Aberrant regulation of HDAC2 may play a pivotal role in the development of liver cancer rendering HDAC2 a relevant target for liver cancer therapy (15). In numerous previous studies, SHH signaling regulated histone acetylation and chromatin (16) and led to carcinogenesis (17). Further studies are still required to ascertain the use of dual inhibition of SHH signaling and HDAC treat liver cancer. In the present 
study, it was demonstrated that the combined use of SHH and HDAC inhibitors effectively treated liver cancer cells in vitro and ex vivo. These studies indicated that $\mathrm{SHH}$ inhibition may be a reasonable strategy to extend the utility of a HDAC inhibitor in liver cancer.

\section{Materials and methods}

Cell culture. The HepG2 cell line was obtained from the Cell Bank, Chinese Academy of Sciences (Shanghai, China). This is a common liver cancer cell line. The HepG2 cell line was derived from a 15-year-old white male with well-differentiated liver cancer. HepG2 cells were cultured in Dulbecco's modified Eagle's medium (DMEM) (HyClone; GE Healthcare Life Sciences, Logan, UT, USA) supplemented with $10 \%$ fetal bovine serum (FBS; Gibco; Thermo Fisher Scientific, Inc., Waltham, MA, USA). The HepG2 cells were cultured in a humidified incubator containing $5 \% \mathrm{CO}_{2}$ at $37^{\circ} \mathrm{C}$.

Cell viability assay and drug combination analysis. Cell viability was assessed by Cell Counting Kit-8 assay (CCK-8; Dojindo Molecular Technologies, Inc., Rockville, MD, USA). Vismodegib and entinostat were purchased from Shanghai Biochempartner Co., Ltd. (Shanghai, China). According to the instructions, HepG2 cells cultured in 96-well plates were treated with an indicated concentration of vismodegib $(0,1,2,4,8$ and $16 \mu \mathrm{M})$ or entinostat $(0,0.5,1,2,4$ and $8 \mu \mathrm{M})$ or a combination of the two, or DMSO for $72 \mathrm{~h}$. The half-maximal inhibitory concentration $\left(\mathrm{IC}_{50}\right)$ values were obtained from dose-response curves with GraphPad Prism software (version 7.00; GraphPad Software, Inc., La Jolla, CA, USA). The synergistic effect was determined by calculating the combination index (CI) using the Calcusyn software program (version 2.1; Biosoft, Great Shelford, UK). Data from cell viability assays were expressed as the fraction of growth inhibition by the single drugs or the combination. Synergism was expressed as a CI value $<1$ and antagonism by a CI value $>1$ at 0.5 fraction affected (FA).

Cell proliferation assay. The effects of the inhibitors on cell growth were evaluated as previously described (18). Briefly, the cells were cultured in 6-well plates at 1,500 cells/well densities and then treated with vismodegib $(4 \mu \mathrm{M})$ or entinostat $(2 \mu \mathrm{M})$ or combination (vismodegib and entinostat at the respective concentrations). The cells were treated for $\sim 14$ days. Then the cells were fixed, stained with crystal violet, and extracted with glacial acetic acid. The optical density (OD) was assessed at $570 \mathrm{~nm}$ by the microplate reader (iMark ${ }^{\mathrm{TM}}$ Microplate Absorbance Reader; Bio-Rad Laboratories, Inc., Hercules, CA, USA).

Soft agar colony formation assay. The colony formation of the liver cancer cells in soft agar medium was performed as previously described (19). Briefly, the cell suspension $\left(2 \times 10^{4}\right.$ cells/well) was mixed with $0.4 \%$ soft agar (BD Biosciences, Franklin Lakes, NJ, USA) prepared with DMEM containing $10 \%$ FBS and layered onto $0.6 \%$ soft agar prepared with DMEM containing $10 \%$ FBS. In addition, liver cancer cells were treated with media supplemented with the indicated drugs. The medium was changed twice a week. The colonies were photographed and the area of these colonies was assessed by Image-Pro Plus software (version 6.0; Media
Cybernetics, Inc., Rockville, MD, USA) at the end of the experiment.

Apoptosis analysis. HepG2 cells were grown in 6-well plates and treated with vismodegib $(4 \mu \mathrm{M})$, entinostat $(2 \mu \mathrm{M})$, combination or DMSO control for $48 \mathrm{~h}$. Following treatment, apoptotic cells were assessed by nuclear morphology and apoptotic cell numbers were detected. Cells exposed to different treatments for $48 \mathrm{~h}$ were stained with acridine orange (AO) and ethidium bromide (EB) as previously described (20), and examined with a fluorescence microscope (Leica Microsystems $\mathrm{GmbH}$, Wetzlar, Germany). Apoptosis in liver cancer cells was analyzed with an Annexin V-FITC Apoptosis Detection Kit (Dojindo Molecular Technologies, Inc., Kumamoto, Japan). The cultured cells were trypsinized, resuspended in Annexin V binding buffer, and incubated with Annexin V and propidium iodide (PI) in the dark. Flow cytometric analysis was performed using a BD Accuri ${ }^{\mathrm{TM}}$ flow cytometer (BD Biosciences, San Jose, CA, USA) to subject the stained cells.

Cell cycle analysis. The treated cells were fixed in ice-cold $70 \%$ ethanol and stored at $4^{\circ} \mathrm{C}$ overnight for cell cycle analysis. After the fixed cells were washed with PBS, they were treated with $100 \mu \mathrm{g} / \mathrm{ml} \mathrm{RNase} \mathrm{A}$ at $37^{\circ} \mathrm{C}$ for $20 \mathrm{~min}$, and stained with $50 \mu \mathrm{g} / \mathrm{ml}$ PI (Dojindo Molecular Technologies, Inc.). Then, the cells were subjected to fluorescence-activated cell sorting. The cell populations that were found in G0/G1, S and G2/M phases were quantified using the ModFit software (version 4.0; Verity Software House, Inc., Topsham, ME, USA).

Protein isolation and western blotting. Cells exposed to vismodegib $(4 \mu \mathrm{M})$ and/or entinostat $(2 \mu \mathrm{M})$ for $48 \mathrm{~h}$ were lysed by RIPA buffer (Nanjing KeyGen Biotech, Co., Ltd., Nanjing, China) containing protease and phosphatase inhibitors. The BCA method was used to quantify the protein of the lysate. The whole cell extracts $(30 \mu \mathrm{g})$ was separated by $8 \%$ SDS-PAGE and the polyvinylidene fluoride (PVDF) membranes were blocking by $5 \%$ skim milk for $2 \mathrm{~h}$ at $4{ }^{\circ} \mathrm{C}$, then were incubated with the following primary antibodies staying overnight at $4^{\circ} \mathrm{C}$ : vinculin (dilution 1:2,000; cat. no. V4139; Sigma-Aldrich, Merck KGaA, Darmstadt, Germany), CDK1 (dilution 1:500; cat. no. 10762-1-AP), cyclin B1 (dilution 1:500; cat. no. 55004-1-AP), Gli1 (dilution 1:500; cat. no. 25733-1-AP), Gli2 (dilution 1:500; cat. no. 18989-1-AP), Gli3 (dilution 1:500; cat. no. 19949-1-AP) (all from ProteinTech Group, Inc., Chicago, IL, USA), cleaved-PARP (dilution 1:1,000; cat. no. 9541), pS6RP ${ }^{\mathrm{s} 255 / 256}$ (dilution 1:1,000; cat. no. 4858), $\mathrm{pAKT}^{\mathrm{s} 473}$ (dilution 1:1,000; cat. no. 4060) and acetyl-histone H3 (dilution 1:1,000; cat. no. 9677) (all from Cell Signaling Technology, Inc., Danvers, MA, USA). Subsequently, they were incubated with horseradish peroxidase-conjugated secondary antibody (dilution 1:1,000; cat. no. A0208; Beyotime Institute of Biotechnology, Shanghai, China), which was followed by Thermo Scientific ${ }^{\mathrm{TM}}$ chemiluminescence (cat. no. 32106; Thermo Fisher Scientific Co., Ltd., Shanghai, China) detection.

Ex vivo culture of patient tumor tissue. The case of a 59-year-old patient with diagnosed primary moderately differentiated liver cancer without treatment history was employed. The acquisition of tumor tissue was executed with 
an Institutional Review Board protocol approved by Binzhou Medical University (Yantai, China) and written informed consent was provided by this patient. The primary liver cancer specimens from this patient who underwent a hepatic segmentectomy were obtained and subjected to ex vivo culture experiments.

For the ex vivo culture, $1 \mathrm{~cm}^{2}$ hemostatic gelatin dental sponges were soaked in the medium, in which DMEM base was supplemented with $10 \%$ FBS, hydrocortisone (1 mg/100 ml; Sigma-Aldrich; Merck KGaA), antibiotic/antimycotic solution (Gibco; Thermo Fisher Scientific, Inc.), and insulin $(1 \mathrm{mg} / 100 \mathrm{ml})$ for $1 \mathrm{~h}$. Then, liver cancer tissues were cut into $1 \mathrm{~mm}^{3}$ blocks, and transferred to the top surface of hemostatic gelatin dental sponges. Tissue blocks were treated with SHH pathway inhibitor vismodegib and HDAC inhibitor entinostat as single-agents or in combination for $48 \mathrm{~h}$, and then fixed with paraformaldehyde. The tissue blocks were embedded in paraffin, sectioned with microtome, and stained with hematoxylin and eosin (H\&E). Immunohistochemistry (IHC) was implemented using antibodies Bcl-2 (dilution 1:200; cat. no. 12789-1-AP), Bax (dilution 1:200; cat. no. 50599-2-Ig) and Ki-67 (dilution 1:400; cat. no. 27309-1-AP) (all from ProteinTech Group, Inc.). The results of the staining were quantified by Image-Pro Plus software.

Statistical analysis. All numerical data were presented as averages and the standard deviation (SD) of the mean. The data was analyzed by one-way analysis of variance (ANOVA) followed by Dunnett's post hoc test. Statistical significance was regarded at $\mathrm{P}<0.05$. All statistical analyses were performed using GraphPad Prism 5.0 (GraphPad Software, Inc., San Diego, CA, USA).

\section{Results}

Combined use of vismodegib and entinostat inhibits the growth of liver cancer cells. Given that the SHH signaling pathway regulated histone acetylation and led to cancinogenesis (20), the liver cancer cell line, HepG2, was chosen for examination. Cell proliferation assay using CCK-8 revealed that the $\mathrm{IC}_{50}$ value of vismodegib for HepG2 cells was $4.012 \mu \mathrm{M}$ (Fig. 1A), and the $\mathrm{IC}_{50}$ value of entinostat for these cells was $1.992 \mu \mathrm{M}$ (Fig. 1A). Then, the HepG2 cells were treated with different concentrations of vismodegib and entinostat, each alone and in combination for $72 \mathrm{~h}$. The median-effect analysis was used to assess the effect of the drug combination on proliferation inhibition. Combined treatment with vismodegib and entinostat resulted in a synergistic increase in proliferation inhibition and synergistic CI value of $<1$ at $0.5 \mathrm{FA}$ in HepG2 cells (Fig. 1B).

We also observed that SHH signaling inhibitor vismodegib as single-agent slightly reduced the viability of HepG2 cells (Fig. 1C). Conversely, the HDAC inhibitor entinostat revealed a moderate inhibitory effect on the viablity of these liver cancer cells (Fig. 1C). However, the combined use of vismodegib and entinostat almost completely suppressed the growth of HepG2 cells (Fig. 1C).

The observation that the combination treatment inhibited cell proliferation in two-dimensional culture conditions led us to further assess the effect of the drug combination in three-dimensional conditions. Inhibition of the SHH pathway by the use of vismodegib alone slightly inhibited colony formation efficiently and inhibition of entinostat exhibited a moderate inhibitory effect. As anticipated, the combined use of vismodegib and entinostat inhibited the formation of colonies in HepG2 cells almost completely (Fig. 1D). These results indicated that dual use of SHH signaling inhibitor vismodegib and HDAC inhibitor entinostat provided a synergistic inhibitory effect on the proliferation of liver cancer cells.

Combined use of vismodegib and entinostat synergistically induces apoptosis in liver cancer cells. To investigate whether apoptosis was the pathway of cell death after treatment, cell morphological changes were observed and the proportion of apoptotic cells was evaluated by AO/EB staining and flow cytometric assays, respectively. The results indicated that only sporadic apoptotic cells were observed in the vehicle group, however, more apoptotic cells were observed in the vismodegib and entinostat single-agent treated groups. The number of apoptotic cells significantly increased in the combined treatment group of HepG2 cells (Fig. 2A). While vismodegib or entinostat alone produced a mild increase in Annexin V-positive cells, combined treatment resulted in significantly increased Annexin V-positive cells in HepG2 cells (Fig. 2B). Consistent with this result, the combination treatment also enhanced the abundance of cleaved-PARP, a marker for active apoptosis, in HepG2 cells. (Fig. 2C).

Combination treatment using vismodegib and entinostat has potent inhibition activity in liver cancer specimens. An ex vivo culture model of liver cancer was employed to assess the therapeutic effect of vismodegib combined with entinostat. Briefly, we dissected fresh surgical specimens of primary liver cancer into $\sim 1 \mathrm{~mm}^{3}$ blocks. These blocks were exposed to vismodegib and entinostat as single-agents or in combination for $48 \mathrm{~h}$ on the absorbable gelatin sponge. The results of histological examination revealed that the tissue structure of vehicle-treated explants was similar to that of the primary tumor tissue (Fig. 3A). The blocks treated with vismodegib and entinostat displayed marked disrupted cellular integrity compared to that in the single-agent treatment groups (Fig. 3A). Consistently, the combination treatment significantly reduced proliferation as determined by Ki-67, and significantly enhanced apoptosis as determined by downregulated Bcl-2 and upregulated Bax (Fig. 3B). Collectively, these data ascertained the potential use of vismodegib and entinostat to treat liver cancer.

Combined use of vismodegib and entinostat synergistically induces G2/M arrest of liver cancer cells. To assess whether the effects of combination treatment on liver cancer cells involved changes in the cell cycle, HepG2 cells were treated with vismodegib and entinostat alone or combined treatment for $48 \mathrm{~h}$. The results revealed that combination treatment significantly increased the number of cells at the $\mathrm{G} 2 / \mathrm{M}$ phase and significantly decreased the number of cells at the $\mathrm{S}$ phase (Fig. 4A). However, an increase of sub-G1 populations was also observed. While vismodegib and entinostat as single-agents led to a slight increase of sub-G1 populations, dual treatment with vismodegib and entinostat resulted in a marked increase of sub-G1 in HepG2 cells (Fig. 4A). The present 


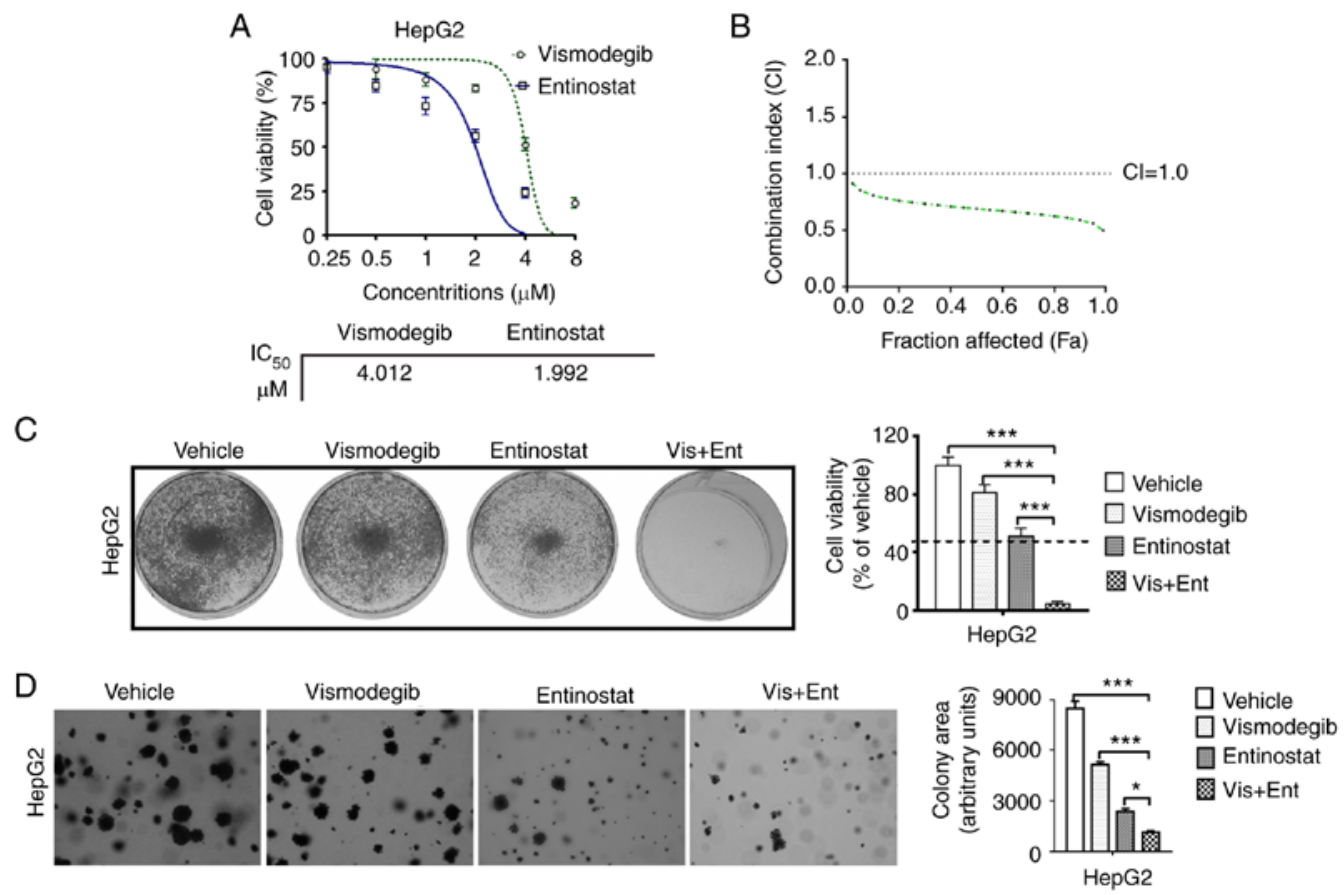

Figure 1. The combined use of vismodegib and entinostat synergistically inhibits the growth of liver cancer cells. (A) The $\mathrm{IC}_{50}$ values of $\mathrm{HepG} 2$ cells treated with vismodegib $(0,1,2,4,8$ and $16 \mu \mathrm{M})$ or entinostat $(0,0.5,1,2,4$ and $8 \mu \mathrm{M})$ for $72 \mathrm{~h}$ were assessed using a CCK-8 assay. (B) The HepG2 cells were treated with indicated drugs. The combination index (CI) values were assessed using the results of the CCK-8 assay and presented with FA combinations. (C) Liver cancer cells cultured in the 6-well plates were treated with the inhibitors as indicated and then stained with crystal violet. (D) Liver cancer cells were cultured on soft agar and were treated with the indicated inhibitors for $\sim 4$ weeks. The colonies were imaged and quantified (magnification, $x 200$ ). The mean \pm SD for 3 independent experiments is presented. ${ }^{*} \mathrm{P}<0.05 ;{ }^{* * *} \mathrm{P}<0.001$. CCK-8, Cell Counting Kit-8; FA, fractions affected.

A
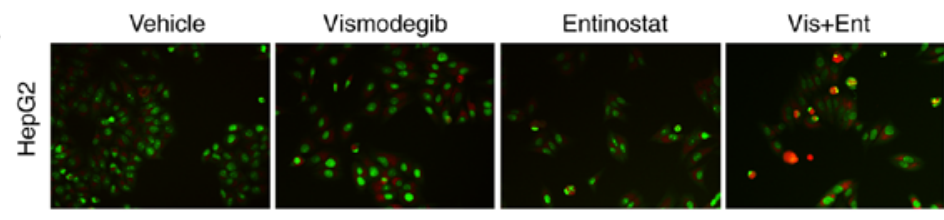

B
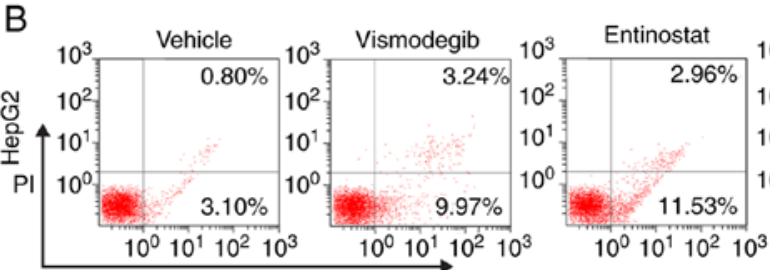

C Vismodegib -+-+
Entinostat --++
HepG2
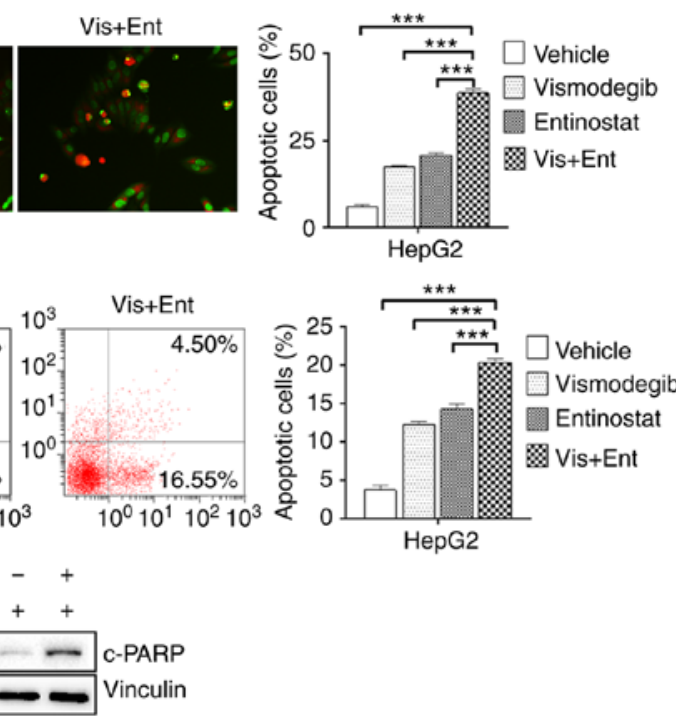

Figure 2. The combined use of vismodegib and entinostat synergistically induces apoptosis in liver cancer cells. (A) Liver cancer cells were treated with vismodegib $(4 \mu \mathrm{M})$ and entinostat $(2 \mu \mathrm{M})$ as single agents or in combination for $48 \mathrm{~h}$. The cells were stained with AO/EB and observed. The percentage of apoptotic cells was examined for each group and the result was expressed as the number of apoptotic cells over the total number of cells counted. Scale bar, $100 \mu \mathrm{m}$. (B) Liver cancer cells were treated with indicated drugs for $48 \mathrm{~h}$ and stained with Annexin V and PI. The mean \pm SD for 3 independent experiments is presented. ${ }^{* * *} \mathrm{P}<0.001$. (C) Cleaved-PARP was analyzed by western blotting in liver cancer cells treated as indicated for $48 \mathrm{~h}$. Vinculin was used as a loading control. AO, acridine orange; EB, ethidium bromide; PI, propidium iodide.

study determined that combination therapy induced G2/M arrest and triggered apoptosis of HepG2 cells. With regards to the biomarkers of the cell cycle, vismodegib combined with entinostat reduced the expression of cyclin B1 and cyclin dependent kinase 1 (CDK1) (Fig. 4B), which further indicated that the combination treatment resulted in $\mathrm{G} 2 / \mathrm{M}$ phase arrest.
Vismodegib as a single agent or in combination with entinostat attenuates PI3K/mTOR signaling. Western blot analysis revealed that vismodegib as a single agent or in combination with entinostat resulted in a marked reduction of the expression of Gli1, Gli2 and Gli3 effectors of SHH signaling in HepG2 cells (Fig. 5A). Notably, a slight effect was observed with 


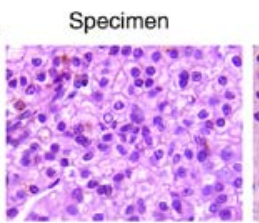

Vehicle
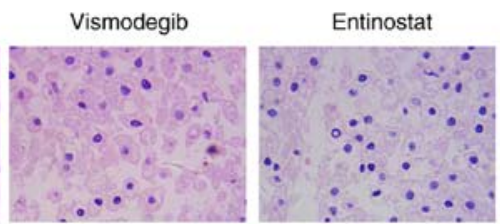

Vis+Ent

B
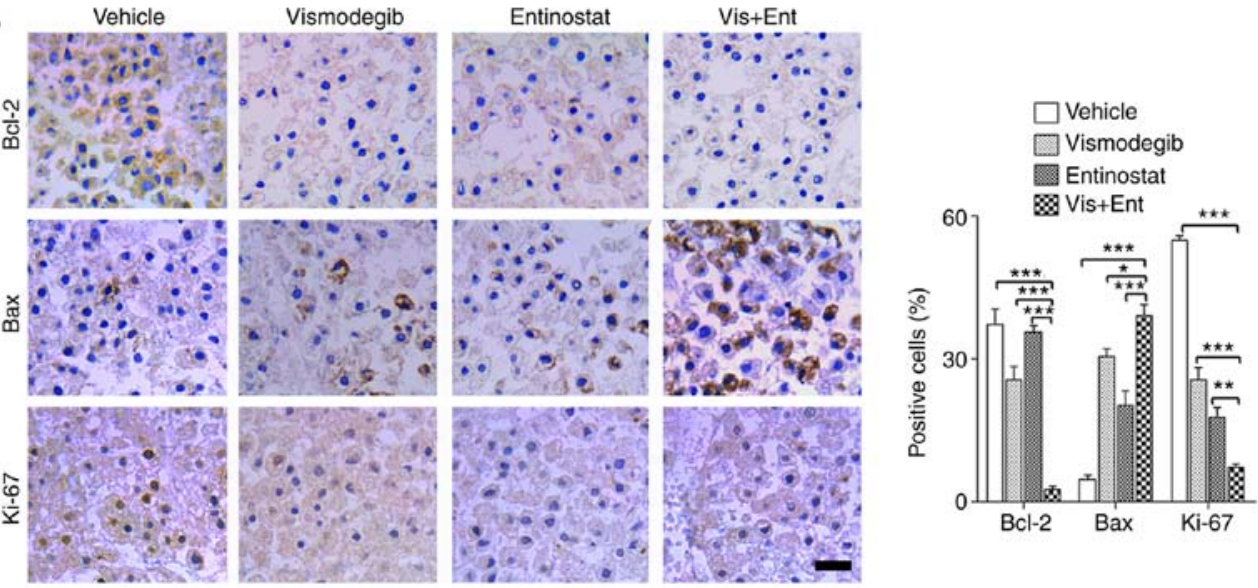

Figure 3. Reaction of primary tumor explants to vismodegib and entinostat as single agents or in combination. (A) Representative H\&E staining images of surgical specimens and tumor explants by ex vivo culture. (B) Representative images of immunohistochemical staining analyses of Ki-67, Bcl-2 and Bax on tumor explants treated with vismodegib $(4 \mu \mathrm{M})$ and entinostat $(2 \mu \mathrm{M})$ as single agents or in combination. Scale bars, $50 \mu \mathrm{m}$. The percentage of positive cell of expression of $\mathrm{Ki}-67, \mathrm{Bcl}-2$ and Bax in each group was examined, and the results were expressed as the number of positive cells expressed over the total number of cells counted. The data are presented as the mean $\pm \mathrm{SD}$ of 3 different tumor explants. ${ }^{*} \mathrm{P}<0.05 ;{ }^{* * *} \mathrm{P}<0.01 ;{ }^{* * * *} \mathrm{P}<0.001$. H\&E, hematoxylin and eosin.

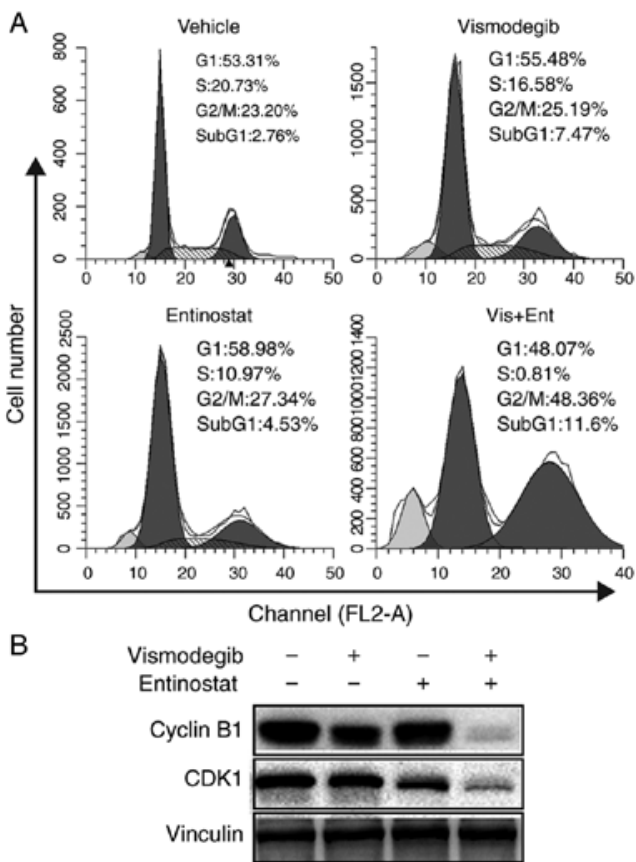

Figure 4. The combined use of vismodegib and entinostat synergistically induces $\mathrm{G} 2 / \mathrm{M}$ arrest of liver cancer cells. (A) HepG2 cells were cultured with vismodegib $(4 \mu \mathrm{M})$ for $24 \mathrm{~h}$, entinostat $(2 \mu \mathrm{M})$ or a combination of these drugs, and analyzed by flow cytometry. The percentages of apoptotic cells in sub-G1 peaks and those of cells in the G1, S and G2/M phases are indicated. (B) Western blot analysis of proteins (cyclin B1 and CDK1) as revealed in liver cancer cells treated with vismodegib $(4 \mu \mathrm{M})$ and entinostat $(2 \mu \mathrm{M})$ as single agents or in combination. Vinculin was used as a loading control.

SHH signaling in liver cancer cells treated with entinostat as a single-agent. In addition, the results revealed that entinostat as a
A

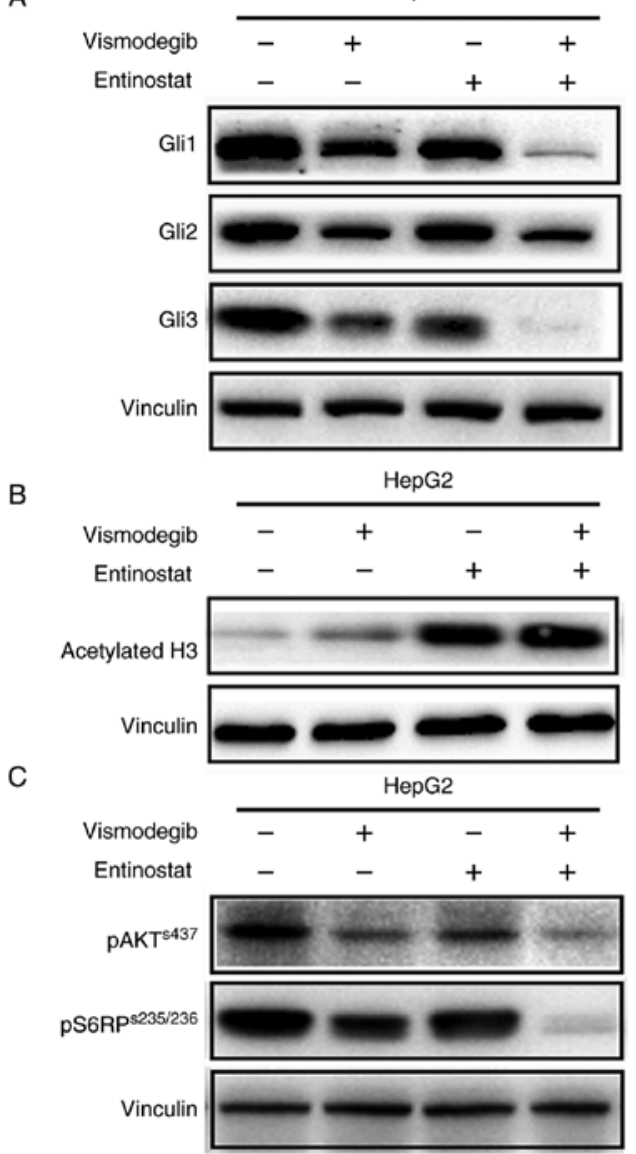

Figure 5. Vismodegib as a single agent or in combination with entinostat sufficiently weakens activation of PI3K/mTOR signaling. (A-C) Western blot analysis of proteins (acetyl-histone 3, Gli1, Gli2, Gli3, pAKT and pS6RP) as indicated in liver cancer cells treated with vismodegib $(4 \mu \mathrm{M})$ and entinostat $(2 \mu \mathrm{M})$ as single agents or in combination for $48 \mathrm{~h}$. Vinculin was used as a loading control. 
single agent or in combination with vismodegib led to a marked increase in acetylated histone 3 in HepG2 cells (Fig. 5B).

It has been reported that inhibition of SHH signaling regulated pancreatic tumorigenesis via inhibition of the PI3K/AKT signaling pathway (21). Thus, it was investigated whether the dual inhibition of the SHH pathway and HDAC inhibited the growth of liver cancer cells via inhibition of the PI3K/AKT signaling pathway. Liver cancer cells, HepG2, were treated with vismodegib or entinostat as single-agents or in combination. The results revealed that vismodegib as a single-agent or in combination with entinostat caused markedly reduced phosphorylated levels of AKT and S6RP, a downstream effector of PI3K/mTOR signaling, in HepG2 cells (Fig. 5C). Collectively, the results of the present study indicated that combined use of inhibitors vismodegib and entinostat may downregulate the $\mathrm{PI} 3 \mathrm{~K} / \mathrm{mTOR}$ signaling.

\section{Discussion}

Liver cancer is a complex and heterogeneous disease associated with genomic aberrations. In order to solve the difficult-to-treat characteristics of liver cancer, an SHH signaling pathway inhibitor and a HDAC inhibitor were used to treat liver cancer cells based on previous research. Our results revealed that dual use of SHH and HDAC inhibitors effectively induced apoptosis, inhibited cell proliferation in HepG2 cells, and promoted cell death in liver cancer cells in an ex vivo culture model of liver cancer.

The aberrant activation of SHH signaling and the mutation of its ligand are closely related to the progression of cancer $(8,22)$. Early clinical trial results have revealed that vismodegib had good efficacy and safety in basal cell carcinoma (23), however, it has been recently revealed that Smo mutation conferred vismodegib resistance to medulloblastoma (24). Recently studies have revealed that vismodegib inhibited the SHH signaling pathway rendering tumor cells sensitive to platinum-based chemotherapy in non-small cell lung cancer (25) and was sensitive to liver cancer radiation therapy (26). However, SHH inhibition in liver cancer with vismodegib is challenging, due to the possible presence of non-canonical Gli activation mechanisms. For the treatment of tumors using SHH signaling inhibitors, a combination therapy is used to increase the therapeutic effect of the inhibitor and sensitivity to tumors. Therefore, in the present study a HDAC inhibitor was used in combination with an $\mathrm{SHH}$ inhibitor to enhance the efficacy of the SHH inhibitor and provide more possibilities for the selection of drug treatment options for liver cancer.

Although high HDAC1 expression is associated with activated $\mathrm{SHH}$ signaling in neural progenitors and medulloblastomas, loss of HDAC activity was revealed to inhibit Hedgehog-dependent growth of neural progenitors and tumor cells $(11,16,27,28)$. HDACs plays a role in regulating many proteins that are closely related to the initiation and progression of cancer. Several HDACs have been revealed to have aberrant expression in liver cancer (15). In the present study concerning gene expression characteristics as a predictor of survival in liver cancer patients, it was determined that HDAC overexpression was associated with lower survival rates in liver cancer patients $(4,29)$. It has been reported that Gli1 and Gli2 are acetylated proteins, and their HDAC-mediated deacetylation was revealed to promote transcriptional activation and positive autoregulation of the loop by Hedgehog-induced upregulation of HDAC1 $(28,30)$. Consistent with this, our present study revealed that the dual use of SHH and HDAC inhibitors could effectively inhibit Gli expression and exert effective antitumor activity in liver cancer cells. In the present study, an ex vivo culture model of surgically resected fresh liver cancer specimens was used to evaluate drug efficacy. Since the cultured tissue explants retained tissue structure and cellularity, as observed in primary tumors, this approach provided a suitable platform to assess acute treatment response to liver cancer. Our results indicated that the combination of vismodegib and entinostat was effective in promoting the death of tumor explant cells.

The present results revealed that inhibition of SHH signaling not only inhibited the growth of liver cancer cells and promoted apoptosis, but also induced G2/M cell cycle arrest. In addition, SHH signaling pro-apoptotic factors (cleaved PARP and Bax) were upregulated, and the activity of anti-apoptotic factors (including Bcl-2) were inhibited. SHH-related pathways do not always work directly, but rather induce complex cascades of networks that intersect with other pathways to function in different biological processes. The PI3K/mTOR signaling pathway is closely related to $\mathrm{SHH}$ (31). Studies have indicated that the PI3K/mTOR signaling has a synergistic effect on $\mathrm{SHH}$ signaling in embryonic development and cancer $(21,31)$. To further investigate the relationship between the PI3K/mTOR and SHH pathways in liver cancer, the results in the present study clearly revealed that combined use of SHH and HDAC inhibitors blocked the activation of the PI3K/mTOR pathway and played an antitumor role. Therefore, it is suggested that the treatment of SHH signaling should consider the effect of $\mathrm{PI} 3 \mathrm{~K} / \mathrm{mTOR}$ pathway.

In summary, our data indicated that HDAC inhibition contributed to the sensitivity of SHH inhibition, and inhibition of PI3K/mTOR by inhibition of SHH and HDAC may play a key role in this synergy. Although the number of liver cancer cell line models and ex vivo models studied in the present study was limited, our data inidcated that the combined use of $\mathrm{SHH}$ and HDAC inhibitors may benefit patients with liver cancer.

\section{Acknowledgements}

Not applicable.

\section{Funding}

The present study was supported by the Shandong Provincial Natural Science Foundation (nos. ZR2013HM047 and ZR201709250448), the Provincial Medicine and Health Science Technology Development Program Shandong (nos. 2017WSB29030 and 2017WSB29031), and the Provincial Higher Education Science Technology Development Program of Shandong (no. J18KB138).

\section{Availability of data and materials}

The datasets used during the present study are available from the corresponding author upon reasonable request. 


\section{Authors' contributions}

DW, JL and HC conceived the project and designed the experiments. JL and HL performed the cell viability assay and the drug combination analysis. HC contributed to the western blotting tests and data analysis. $\mathrm{HC}$ and YSh were responsible for the cell proliferation assay and the soft agar colony formation assay. HS contributed to the apoptosis and cell cycle analysis experiments. YL, YSu and YW contributed to the experiments about the clinical specimen. HC and DW wrote the manuscript. All authors read and approved the manuscript and agree to be accountable for all aspects of the research in ensuring that the accuracy or integrity of any part of the work are appropriately investigated and resolved.

\section{Ethics approval and consent to participate}

The acquisition of tumor tissue was executed with an Institutional Review Board protocol approved by Binzhou Medical University (Yantai, China) and written informed consent was provided by this patient.

\section{Patient consent for publication}

Not applicable.

\section{Competing interests}

The authors state that they have no competing interests.

\section{References}

1. Chen W, Zheng R, Baade PD, Zhang S, Zeng H, Bray F, Jemal A Yu XQ and He J: Cancer statistics in China, 2015. CA Cancer J Clin 66: 115-132, 2016.

2. Siegel RL, Miller KD and Jemal A: Cancer statistics, 2018. CA Cancer J Clin 68: 7-30, 2018.

3. Heimbach JK, Kulik LM, Finn RS, Sirlin CB, Abecassis MM, Roberts LR, Zhu AX, Murad MH and Marrero JA: Aasld guidelines for the treatment of hepatocellular carcinoma. Hepatology 67: 358-380, 2018.

4. Choi KJ, Baik IH, Ye SK and Lee YH: Molecular targeted therapy for hepatocellular carcinoma: Present status and future directions. Biol Pharm Bull 38: 986-991, 2015.

5. Wang Y, Han C, Lu L, Magliato S and Wu T: Hedgehog signaling pathway regulates autophagy in human hepatocellular carcinoma cells. Hepatology 58: 995-1010, 2013.

6. Wang Q, Huang S, Yang L, Zhao L, Yin Y, Liu Z, Chen Z and Zhang H: Down-regulation of Sonic Hedgehog signaling pathway activity is involved in 5-fluorouracil-induced apoptosis and motility inhibition in Hep3B cells. Acta Biochim Biophys Sin 40: 819-829, 2008.

7. Li P, Lee EH, Du F, Gordon RE, Yuelling LW, Liu Y, Ng JM, Zhang H, Wu J, Korshunov A, et al: Nestin mediates hedgehog pathway tumorigenesis. Cancer Res 76: 5573-5583, 2016.

8. Hanaoka J, Shimada M, Utsunomiya T, Morine Y, Imura S, Ikemoto T and Mori H: Significance of sonic Hedgehog signaling after massive hepatectomy in a rat. Surg Today 43: 300-307, 2013

9. Lauth M, Bergstrom A, Shimokawa T and Toftgard R: Inhibition of gli-mediated transcription and tumor cell growth by small-molecule antagonists. Proc Natl Acad Sci USA 104: 8455-8460, 2007.

10. Axelson M, Liu K, Jiang X, He K, Wang J, Zhao H, Kufrin D, Palmby T, Dong Z, Russell AM, et al: U.S. Food and drug administration approval: Vismodegib for recurrent, locally advanced, or metastatic basal cell carcinoma. Clin Cancer Res 19: 2289-2293, 2013

11. Lee SJ, Lindsey S, Graves B, Yoo S, Olson JM and Langhans SA: Sonic Hedgehog-induced histone deacetylase activation is required for cerebellar granule precursor hyperplasia in medulloblastoma. PLoS One 8: e71455, 2013.
12. Anestopoulos I, Voulgaridou GP, Georgakilas AG, Franco R, Pappa A and Panayiotidis MI: Epigenetic therapy as a novel approach in hepatocellular carcinoma. Pharmacol Ther 145: 103-119, 2015.

13. Hardy T and Mann DA: Epigenetics in liver disease: From biology to therapeutics. Gut 65: 1895-1905, 2016.

14. Xie HJ, Noh JH, Kim JK, Jung KH, Eun JW, Bae HJ, Kim MG, Chang YG, Lee JY, Park H, et al: HDAC1 inactivation induces mitotic defect and caspase-independent autophagic cell death in liver cancer. PLoS One 7: e34265, 2012.

15. Noh JH, Jung KH, Kim JK, Eun JW, Bae HJ, Xie HJ, Chang YG, Kim MG, Park WS, Lee JY, et al: Aberrant regulation of HDAC2 mediates proliferation of hepatocellular carcinoma cells by deregulating expression of G1/S cell cycle proteins. PLoS One 6: e28103, 2011.

16. Wu M, Hernandez M, Shen S, Sabo JK, Kelkar D, Wang J, O'Leary R, Phillips GR, Cate HS and Casaccia P: Differential modulation of the oligodendrocyte transcriptome by sonic hedgehog and bone morphogenetic protein 4 via opposing effects on histone acetylation. J Neurosci 32: 6651-6664, 2012.

17. Valdora F, Banelli B, Stigliani S, Pfister SM, Moretti S, Kool M, Remke M, Bai AH, Brigati C, Hielscher T, et al: Epigenetic silencing of $D K K 3$ in medulloblastoma. Int J Mol Sci 14: 7492-7505, 2013.

18. Wang D, Li C, Zhang Y, Wang M, Jiang N, Xiang L, Li T, Roberts TM, Zhao JJ, Cheng H, et al: Combined inhibition of pi3k and parp is effective in the treatment of ovarian cancer cells with wild-type PIK3CA genes. Gynecol Oncol 142: 548-556, 2016.

19. Herynk MH, Stoeltzing O, Reinmuth N, Parikh NU, Abounader R, Laterra J, Radinsky R, Ellis LM and Gallick GE: Down-regulation of c-Met inhibits growth in the liver of human colorectal carcinoma cells. Cancer Res 63: 2990-2996, 2003.

20. Chao H, Wang L, Hao J, Ni J, Chang L, Graham PH, Kearsley JH and Li Y: Low dose histone deacetylase inhibitor, LBH589, potentiates anticancer effect of docetaxel in epithelial ovarian cancer via PI3K/Akt pathway in vitro. Cancer Lett 329: 17-26, 2013.

21. Song Z, Du Y and Tao Y: Blockade of sonic Hedgehog signaling decreases viability and induces apoptosis in retinoblastoma cells: The key role of the pi3k/akt pathway. Oncol Lett 14: 4099-4105, 2017.

22. Huang S, He J, Zhang X, Bian Y, Yang L, Xie G, Zhang K, Tang W, Stelter AA, Wang Q, et al: Activation of the hedgehog pathway in human hepatocellular carcinomas. Carcinogenesis 27: 1334-1340, 2006.

23. Rudin CM: Vismodegib. Clin Cancer Res 18: 3218-3222, 2012.

24. Yauch RL, Dijkgraaf GJ, Alicke B, Januario T, Ahn CP, Holcomb T, Pujara K, Stinson J, Callahan CA, Tang T, et al: Smoothened mutation confers resistance to a Hedgehog pathway inhibitor in medulloblastoma. Science 326: 572-574, 2009.

25. Giroux Leprieur E, Vieira T, Antoine M, Rozensztajn N, Rabbe N, Ruppert AM, Lavole A, Cadranel J and Wislez M: Sonic Hedgehog pathway activation is associated with resistance to platinum-based chemotherapy in advanced non-small-cell lung carcinoma. Clin Lung Cancer 17: 301-308, 2016.

26. Tsai CL, Hsu FM, Tzen KY, Liu WL, Cheng AL and Cheng JC: Sonic Hedgehog inhibition as a strategy to augment radiosensitivity of hepatocellular carcinoma. J Gastroenterol Hepatol 30: 1317-1324, 2015

27. Chun SG, Zhou W and Yee NS: Combined targeting of histone deacetylases and hedgehog signaling enhances cytoxicity in pancreatic cancer. Cancer Biol Ther 8: 1328-1339, 2009.

28. Canettieri G, Di Marcotullio L, Greco A, Coni S, Antonucci L, Infante P, Pietrosanti L, De Smaele E, Ferretti E, Miele E, et al: Histone deacetylase and Cullin3-REN ${ }^{\text {KCTD11 }}$ ubiquitin ligase interplay regulates Hedgehog signalling through Gli acetylation. Nat Cell Biol 12: 132-142, 2010.

29. Lee JS, Chu IS, Heo J, Calvisi DF, Sun Z, Roskams T, Durnez A, Demetris AJ and Thorgeirsson SS: Classification and prediction of survival in hepatocellular carcinoma by gene expression profiling. Hepatology 40: 667-676, 2004.

30. Hay JF, Lappin K, Liberante F, Kettyle LM, Matchett KB, Thompson A and Mills KI: Integrated analysis of the molecular action of Vorinostat identifies epi-sensitised targets for combination therapy. Oncotarget 8: 67891-67903, 2017.

31. Chen JS, Huang XH, Wang Q, Huang JQ, Zhang LJ, Chen XL, Lei J and Cheng ZX: Sonic Hedgehog signaling pathway induces cell migration and invasion through focal adhesion kinase/AKT signaling-mediated activation of matrix metalloproteinase (MMP)-2 and MMP-9 in liver cancer. Carcinogenesis 34: 10-19, 2013. 